\title{
Understanding the Electronic Structures and Absorption Properties of Porphyrin Sensitizers YD2 and YD2-0-C8 for Dye-Sensitized Solar Cells
}

Li-Heng Han ${ }^{1}$, Cai-Rong Zhang ${ }^{1,2, *}$, Jian-Wu Zhe ${ }^{3}$, Neng-Zhi Jin ${ }^{3}$, Yu-Lin Shen ${ }^{3}$, Wei Wang ${ }^{1}$, Ji-Jun Gong ${ }^{1}$, Yu-Hong Chen ${ }^{1,2}$ and Zi-Jiang Liu ${ }^{4}$

1 Department of Applied Physics, Lanzhou University of Technology, Lanzhou 730050, Gansu, China; E-Mails: hanlh130@163.com (L.-H.H.); wangwei3057@163.com (W.W.); gongjijun@163.com (J.-J.G.); chenyh@lut.cn (Y.-H.C.)

2 State Key Laboratory of Gansu Advanced Non-ferrous Metal Materials, Lanzhou University of Technology, Lanzhou 730050, Gansu, China

3 Gansu Computing Center, Lanzhou, Gansu 730030, China; E-Mails: zjw@gspcc.com (J.-W.Z.); jin_n_z@163.com (N.-Z.J.); shenyl@mail.gspcc.com (Y.-L.S.)

4 Department of Physics, Lanzhou City University, Lanzhou 730070, Gansu, China; E-Mail: liuzj_scu@126.com

* Author to whom correspondence should be addressed; E-Mail: zhcrxy@lut.cn; Tel.: +86-931-2973-780; Fax: +86-931-2976-040.

Received: 19 August 2013; in revised form: 20 September 2013 / Accepted: 23 September 2013 / Published: 10 October 2013

\footnotetext{
Abstract: The electronic structures and excitation properties of dye sensitizers determine the photon-to-current conversion efficiency of dye sensitized solar cells (DSSCs). In order to understand the different performance of porphyrin dye sensitizers YD2 and YD2-o-C8 in DSSC, their geometries and electronic structures have been studied using density functional theory (DFT), and the electronic absorption properties have been investigated via time-dependent DFT (TDDFT) with polarizable continuum model for solvent effects. The geometrical parameters indicate that YD2 and YD2-o-C8 have similar conjugate length and charge transfer (CT) distance. According to the experimental spectra, the HSE06 functional in TDDFT is the most suitable functional for describing the Q and B absorption bands of porphyrins. The transition configurations and molecular orbital analysis suggest that the diarylamino groups are major chromophores for effective CT excitations (ECTE), and therefore act as electron donor in photon-induced electron injection in DSSCs. The analysis of excited states properties and the free energy changes for electron injection
} 
support that the better performance of YD2-o-C8 in DSSCs result from the more excited states with ECTE character and the larger absolute value of free energy change for electron injection.

Keywords: porphyrin dye sensitizers; excited states; electronic structures; density functional theory; absorption spectra

\section{Introduction}

In recent years, dye-sensitized solar cells (DSSCs), as a novel technology for the conversion of solar energy into electricity, have attracted tremendous and continuous research interest because of easy fabrication, lower cost, and relatively higher efficiency comparing to other photovoltaic technology [1-5]. It has been found that all of the main components in DSSCs, including dye sensitizers, anode, and cathode, as well as electrolyte, can affect the photon-to-current conversion efficiency (PCE). Specifically, the dye sensitizers, which have the function of light harvesting and photon-excited electron injection, have a significant influence on the PCE [6-11]. The DSSCs applied ruthenium-complex dyes exhibit more than 10\% PCE due to their broad absorption, the longer life-time of exciton, and their long-term chemical stability $[4,12,13]$. However, the rare resource of metal $\mathrm{Ru}$ and other environmental problems will limit the further development of Ru-based DSSCs for commercialization. Therefore, in order to improve the PCE and to overcome the drawback of Ru-complex sensitizers, the organic dye sensitizers, including cyanines [14-16], hemicyanines [17,18], triarylamins [8,19,20], perylenes [21-25], coumarins [26-28], porphyrins [29-34], squaraines [35-37], indoline [38,39], and azulene-based dyes [40], etc. were developed because of their high molar absorption coefficient, relatively simple synthetic procedure, easily modified structures and lower cost. Among them, porphyrins are viewed as one of the more promising dye sensitizers for DSSCs because porphyrin derivatives have better photosynthesis performance, strong UV-visible light absorption, and allow for easy modification/design of their structures $[41,42]$.

The promising development of various porphyrin sensitizers to enhance the PCE was activated by over 7\% PCE of porphyrin sensitized DSSCs $[43,44]$. During the development of porphyrin sensitizer, the PCE of DSSCs has been improved continually since the reported DSSC with $2.6 \%$ PCE was sensitized by copper chlorophyllin [45]. The further optimized DSSCs with zinc porphyrin sensitizer YD2-o-C8, co-sensitized with an organic dye Y123, using a cobalt-based electrolyte, attained PCE of $12.3 \%$ [46]. This stimulates the investigation of the further development of porphyrin sensitizers to promote the device performance of porphyrin-sensitized DSSCs. For instance, diketopyrrolopyrrole-zinc prophyrin, combining a zinc porphyrin and a dikepyrrolopyrrole fragments which display complementary absorption features into a fully conjugated push-pull systems, achieved 7.74\% PCE [47,48]. Based upon analysis of the reported works on porphyrin-based dye sensitizers, it has been recognized that the intrinsic advantages of porphyrin-based dyes are their rigid molecular structures with large absorption coefficients in the visible and infrared region and their four meso and eight $\beta$ reaction sites, which are available for tuning of the optical, physical, electrochemical and photovoltaic properties of porphyrins [49]. 
Further developments of the novel dye sensitizer depend on the quantitative knowledge of dye sensitizers $[9,11,50]$. The theoretical investigations of the physical properties of dye sensitizers are very important to disclose the relationships among the performance, structures and the properties. For instance, on the basis of density functional theory (DFT) calculations for the chemical structures and exciton binding energies of several pure organic dyes, the novel organic triphenylamine-based dye sensitizer EB-01 was designed, and over 9\% of PCE was achieved by EB-01 sensitized DSSC [51]. To further design the porphyrin dye sensitizers, it should be understood why porphyrin dyes, especially YD2-o-C8, perform better than that of Ru-complex dye sensitizers, and why the dye structures and the related photophysical properties strongly influence the overall PCE. To answer these questions, it is necessary to accurately calculate electronic structures and excitation properties. However, it has been found that the suitable functional for charge transfer (CT) excited states depends on the system of dye sensitizers under study [52]. For instance, the appropriate functionals for triphenylamine and tetrahydroquinoline dyes are BHandH and CAM-B3LYP, respectively [53-56]. While for five kinds of representative dyes (L0, D4, D5, C217, and JK2), Pastore et al. reported that the MPW1K and CAM-B3LYP functionals represent a valuable tool of comparable accuracy to that of high level $a b$ initio methods [57]. Generally, porphyrins show intense Soret bands at 400-450 nm and moderate $\mathrm{Q}$ bands at 500-650 $\mathrm{nm}$ [58]. The transition configurations of different bands involve different contribution of molecular orbitals (MOs), implying a different CT character. In this paper, YD2 [30] and YD2-o-C8 [46] were selected as representative porphyrin dye sensitizers, and their chemical structures are presented in Scheme 1. Under the framework of time dependent density functional theory (TDDFT), the suitable functional for describing CT excited states of porphyrin dyes were carefully selected based on experimental results. Based upon reliable calculations, the electronic structures and photophysical properties of YD2 and YD2-o-C8 were analyzed.

Scheme 1. Structures of dye sensitizers YD2 and YD2-o-C8.

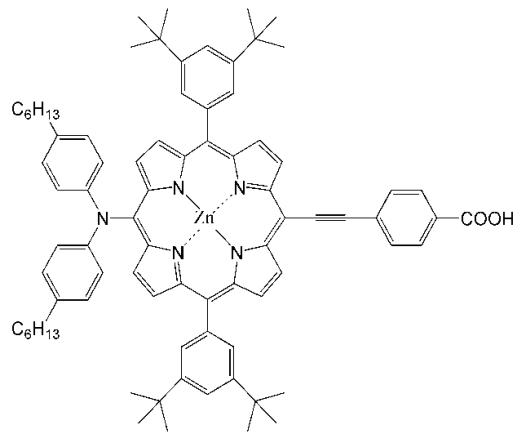

YD2

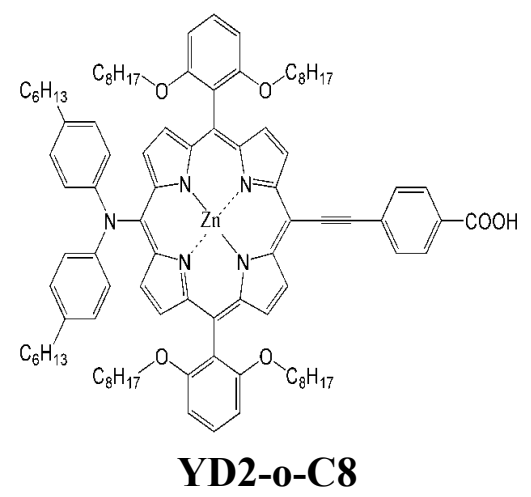

YD2-0-C8

\section{Results and Discussion}

\subsection{Geometrical Structures}

The optimized geometries of YD2 and YD2o-C8 are shown in Figure 1, where the hydrogen atoms were omitted for clarity. YD2 consists of a diarylamino group with two hexyl chains attached to the porphyrin ring acting as an electron donor, phenylethynyl group as a part of bridge, the carboxylic acid moiety as an acceptor, and the porphyrin chromophore constitutes the $\pi$ bridge in this particular donor 
$\pi$-conjugate-bridge acceptor (D- $\pi$-A) structure [59]. The structure of YD2-o-C8 is quite similar to that of YD2. The structural feature of YD2-o-C8 involves long alkoxyl chains in the ortho-positions of the meso-phenyls, which envelope the porphyrin ring to decrease the degree of dye aggregation and to block the approach of the electrolyte to the $\mathrm{TiO}_{2}$ surface [60-62]. The selected geometrical parameters are listed in Tables S1 and S2 in Supplementary Information. The corresponding bond lengths, bond angles, and dihedrals are very similar. For instance, the bond lengths of $\mathrm{Zn}-\mathrm{N}$ in YD2 and YD2-o-C8 are about $2.04 \AA$, and the bond angles of $\mathrm{C} 19-\mathrm{N} 21-\mathrm{C} 25$ are about $122.0^{\circ}$. But, the difference of dihedral C39-C53-C52-C55, which is induced by the substituting alkoxyl chains in YD2-o-C8 for tert-butyl group in YD2, is about $30^{\circ}$ because of steric hindrance. Furthermore, the corresponding geometrical parameters of YD2 are also close to that of YD1 [63]. Therefore, the substitution at ortho-positions of the meso-phenyls has slight effects on the geometry of porphyrins framework. In addition, the quasi-coplanarity between acceptor group (carboxylic acid moiety) and conjugate bridge is favorable for intramolecular charge transfer (IMCT) [64]. The twist between diarylamino group and porphyrin cycle, which results from the orbital hybridiazation of $\mathrm{N}$ in diarylamino group, limits the electron donating ability [48]. The distance between $\mathrm{N}$ in diarylamino group and $\mathrm{C}$ in $\mathrm{COOH}$ can be defined as the conjugate length, which can describe the CT distance to some extent [56]. The conjugate lengths of YD2 and YD2-o-C8 (about $16.7 \mathrm{~nm}$ ) indicate similar CT distance at the interface between semiconductor and dye sensitizers. Interestingly, for YD2 and YD2-o-C8, the inverse of IP optimized range-separation parameter $(1 / \omega, 17.6 \mathrm{~nm})$ is close to the conjugate lengths. The relationship between IP optimized range-separation parameter and conjugate length is similar to that of oligoacenes, polyenes, and oligothiophenes [65].

Figure 1. The optimized geometrical structures of YD2 and YD2-o-C8 (Hydrogen atoms have been omitted for clarity; gray circles: $\mathrm{C}$; blue circles: $\mathrm{N}$; red circles: $\mathrm{O}$; light blue circles: $\mathrm{Zn}$ ).

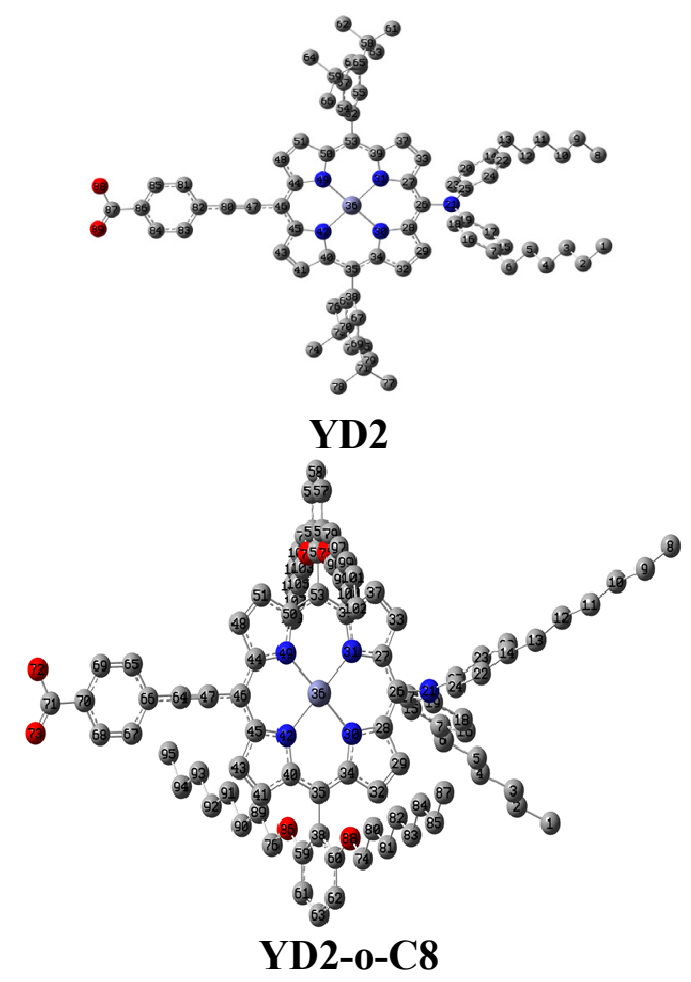




\subsection{Functional Selection for TDDFT}

The UV-vis absorption spectra is the most convenient available experimental data, which can be adopted as the benchmark for selection of suitable TDDFT functional for excited properties of dye sensitizers. For porphyrins, the first absorption band was usually denoted as Q band, while the transitions with the highest oscillator strengths were designated as the B-bands [63]. The calculated absorption $\lambda_{\max }(\mathrm{nm} / \mathrm{eV})$, absolute errors $(\mathrm{AE}$, in $\mathrm{nm} / \mathrm{eV})$, arithmetic mean absolute errors (AMAE, in $\mathrm{nm} / \mathrm{eV}$ ), and mean square error $\sigma$ (in $\mathrm{eV}$ ) of YD2 were listed in Table 1. The data indicates that the most accurate functional for B and Q bands are HSE06 and LC- $\omega$ PBE, respectively. Averagely, HSE06 generate the smallest AMAE for these bands (about $0.11 \mathrm{eV}$ ) and $\sigma$ (about $0.11 \mathrm{eV}$ ) then the smaller AMAE of LC- $\omega$ PBE is about $0.19 \mathrm{eV}$. The calculations with MPW1K, BMK, and $\omega$ B97XD functionals for YD2-o-C8 were not conducted because their AE were large. The calculated results for YD2-o-C8 were listed in Table 2. The data indicates that the most accurate functional for B and Q bands are OPT-LC- $\omega$ PBE and LC- $\omega$ PBE, respectively. However, again, HSE06 generate the smallest AMAE (about $0.13 \mathrm{eV}$ ) and $\sigma$ (about $0.14 \mathrm{eV}$ ). Though LC- $\omega$ PBE generates the smallest AE for Q band, the $\mathrm{AE}$ for $\mathrm{B}$ band is quite remarkable. The simulated spectra are presented in Figure 2. Apparently, the experimental spectra's character, including $\lambda_{\max }$ and line shape (relative strength), is well reproduced by the calculation with HSE06 functional. So the HSE06 functional is the most suitable functional for YD2 and YD2-o-C8 to describe their excitations.

Table 1. The calculated absorption $\lambda_{\max }$ (in $\mathrm{nm} / \mathrm{eV}$ ) and the absolute errors (AE, in $\mathrm{nm} / \mathrm{eV}$ ) of $\mathrm{B}$ and $\mathrm{Q}$ bands for YD2 with different functionals in TDDFT, the arithmetic mean absolute errors (AMAE, in $\mathrm{nm} / \mathrm{eV}$ ) and mean square error $\sigma$ (in $\mathrm{eV}$ ) are also listed.

\begin{tabular}{|c|c|c|c|c|c|c|}
\hline \multirow{2}{*}{ Functionals } & \multicolumn{2}{|c|}{$\lambda_{\max }$} & \multicolumn{2}{|c|}{$\mathbf{A E}$} & \multirow{2}{*}{ AMAE } & \multirow{2}{*}{$\sigma$} \\
\hline & B & $\mathbf{Q}$ & B & $\mathbf{Q}$ & & \\
\hline CAM-B3LYP & $397 / 3.12$ & $585 / 2.12$ & $46 / 0.32$ & $61 / 0.20$ & $53.5 / 0.26$ & 0.267 \\
\hline M062X & $397 / 3.12$ & $573 / 2.17$ & $46 / 0.32$ & $73 / 0.25$ & $59.5 / 0.29$ & 0.287 \\
\hline PBE0 & $481 / 2.58$ & $902 / 1.37$ & $38 / 0.22$ & $256 / 0.55$ & $147 / 0.39$ & 0.477 \\
\hline BMK & $403 / 3.08$ & $582 / 2.13$ & $40 / 0.28$ & $64 / 0.21$ & $52 / 0.25$ & 0.247 \\
\hline$\omega \mathrm{B} 97 \mathrm{XD}$ & $391 / 3.17$ & $595 / 2.08$ & $52 / 0.37$ & $51 / 0.16$ & $51.5 / 0.27$ & 0.285 \\
\hline MPW1K & $401 / 3.09$ & $575 / 2.16$ & $42 / 0.29$ & $71 / 0.24$ & $56.5 / 0.27$ & 0.266 \\
\hline LC- $\omega \mathrm{PBE}$ & $399 / 3.11$ & $628 / 1.98$ & $44 / 0.31$ & $18 / 0.07$ & $31 / 0.19$ & 0.225 \\
\hline OPT-LC- $\omega$ PBE & $475 / 2.61$ & $874 / 1.42$ & $32 / 0.19$ & $228 / 0.50$ & $130 / 0.35$ & 0.378 \\
\hline HSE06 & $423 / 2.93$ & $677 / 1.83$ & $20 / 0.13$ & $31 / 0.09$ & $25.5 / 0.11$ & 0.112 \\
\hline Experiment & $443 / 2.80$ & $646 / 1.92$ & - & - & - & - \\
\hline
\end{tabular}


Table 2. The calculated absorption $\lambda_{\max }(\mathrm{nm} / \mathrm{eV})$ and the absolute errors $(\mathrm{AE}$, in $\mathrm{nm} / \mathrm{eV})$ of $\mathrm{B}$ and $\mathrm{Q}$ bands for YD2-o-C8 with different functionals in TDDFT, the arithmetic mean absolute errors (AMAE, in $\mathrm{nm} / \mathrm{eV}$ ) and mean square error $\sigma$ (in $\mathrm{eV}$ ) are also listed.

\begin{tabular}{cccccccc}
\hline \multirow{2}{*}{ Functionals } & \multicolumn{2}{c}{$\lambda_{\max }$} & & \multicolumn{2}{c}{ AE } & \multirow{2}{*}{ AMAE } & \multirow{2}{*}{$\boldsymbol{\sigma}$} \\
\cline { 2 - 3 } & $\mathbf{B}$ & $\mathbf{Q}$ & & $\mathbf{B}$ & $\mathbf{Q}$ & & \\
\hline CAM-B3LYP & $397 / 3.12$ & $592 / 2.09$ & & $51 / 0.35$ & $53 / 0.17$ & $52 / 0.26$ & 0.275 \\
M062X & $397 / 3.12$ & $579 / 2.14$ & & $51 / 0.35$ & $66 / 0.22$ & $68.5 / 0.29$ & 0.292 \\
PBE0 & $477 / 2.60$ & $879 / 1.41$ & & $29 / 0.17$ & $234 / 0.51$ & $131.5 / 0.34$ & 0.380 \\
LC- $\omega$ PBE & $399 / 3.11$ & $632 / 1.96$ & & $49 / 0.34$ & $17 / 0.04$ & $33 / 0.19$ & 0.242 \\
OPT-LC- $\omega$ PBE & $472 / 2.63$ & $853 / 1.45$ & & $24 / 0.14$ & $208 / 0.47$ & $116 / 0.31$ & 0.347 \\
HSE06 & $420 / 2.95$ & $671 / 1.85$ & & $28 / 0.18$ & $26 / 0.07$ & $27 / 0.13$ & 0.137 \\
Experiment & $448 / 2.77$ & $645 / 1.92$ & - & - & - & - \\
\hline
\end{tabular}

Figure 2. The simulated absorption spectra for YD2 and YD2-o-C8 dyes based upon TDDFT results calculated with different functionals. The experimental measured curves [46] are also included.
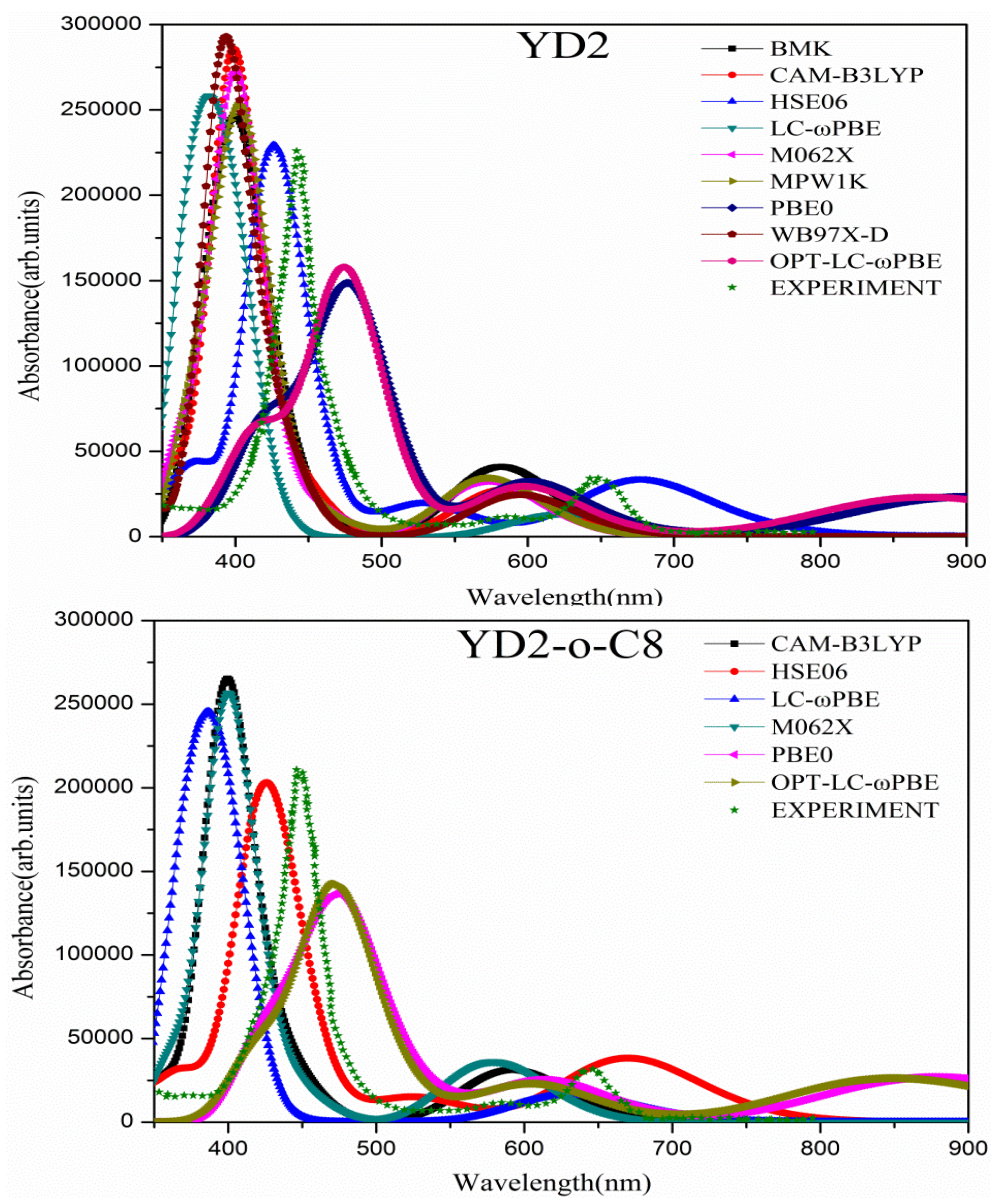

\subsection{Electronic Structures}

The highest occupied molecular orbital (HOMO) and the lowest unoccupied molecular orbital (LUMO) energies of better dye sensitizers are required to locate suitable values for matching the conduction band edge of semiconductor and redox potential of electrolyte in DSSCs. The HOMO level 
corresponds to the ground state oxidation potential (GSOP) of dye sensitizer [66], and the larger GSOP increase the driving force for the reduction of oxidized dye [67]. The HSE06 functional calculated frontier MO eigenvalues and the HOMO-LUMO gaps, as well as isodensity plots of frontier MOs of YD2 and YD2-o-C8 in THF are shown in Figures 3 and 4, respectively. For ZnTPP, the HOMO and HOMO -1 have $a_{2 u}$ and $a_{1 u}$ symmetry, respectively, while the degenerate LUMOs (LUMO, $\mathrm{LUMO}+1$, and LUMO + 2) have $\mathrm{e}_{\mathrm{g}}$ symmetry. For YD2, the eigenvalue of HOMO -4 is very close to that of $\mathrm{HOMO}-3$, only about $0.08 \mathrm{eV}$ difference. The $\mathrm{HOMO}-2$, lying at about $-5.35 \mathrm{eV}$, mixes the MOs of diarylamino and phenylethynyl groups with porphyrin $\mathrm{a}_{2 \mathrm{u}}$ orbital, which has electron density that located on the bound $\alpha$ position. The HOMO -1 , which is about $0.07 \mathrm{eV}$ above HOMO -2 , remains relatively unperturbed local porphyrin $\mathrm{a}_{1 \mathrm{u}}$ orbital due to the mismatching of symmetry, and this is different with the mixed MOs of diarylamino and phenylethynyl groups with porphyrin (B3LYP/6-31G(d) results [46]). The difference can be understood from the different DFT functional [68]. The HOMO, locating at about $-4.85 \mathrm{eV}$, is also mixed orbital which mainly contributed by diarylamino and porphyrin $\mathrm{a}_{2 \mathrm{u}}$ orbital. The LUMO and LUMO $+2 \mathrm{mix}$ the MOs of phenylethynyl carboxylic acid with porphyrin $e_{g}$ orbital. But the LUMO +2 contains more phenylethynyl carboxylic acid derived orbital character compared with the porphyrin based $e_{g}$ orbital. Conversely, the LUMO contains a great contribution of the $\mathrm{e}_{\mathrm{g}}$ derived orbital than from the phenylethynyl carboxylic acid MO. The LUMO +1 , localizing on porphyrin, keeps the unperturbed $\mathrm{e}_{\mathrm{g}}$ character. The frontier MOs characters of YD2-o-C8 are quite similar to that of YD2. The HOMO - 1 and HOMO - 2, the HOMO -3 and HOMO -4 of YD2-o-C8 are quasi-degenerate, respectively. Furthermore, the substitution of tert-butyl groups in YD2 by octyloxy groups in YD2o-C8 increase HOMO about $0.140 \mathrm{eV}$ and LUMO about $0.138 \mathrm{eV}$ and thus reduce the HOMO-LUMO gap about $0.002 \mathrm{eV}$, that is to say, introducing octyloxy groups which have long alkyl chains decrease the energy gap very slightly. The increase of orbital energies of YD2-o-C8 may be rationalized by considering the electron-donor character of octyloxy groups.

Figure 3. The calculated frontier molecular orbitals energies and HOMO-LUMO gap at the HSE06/6-31G (d,p) level in THF solvent.

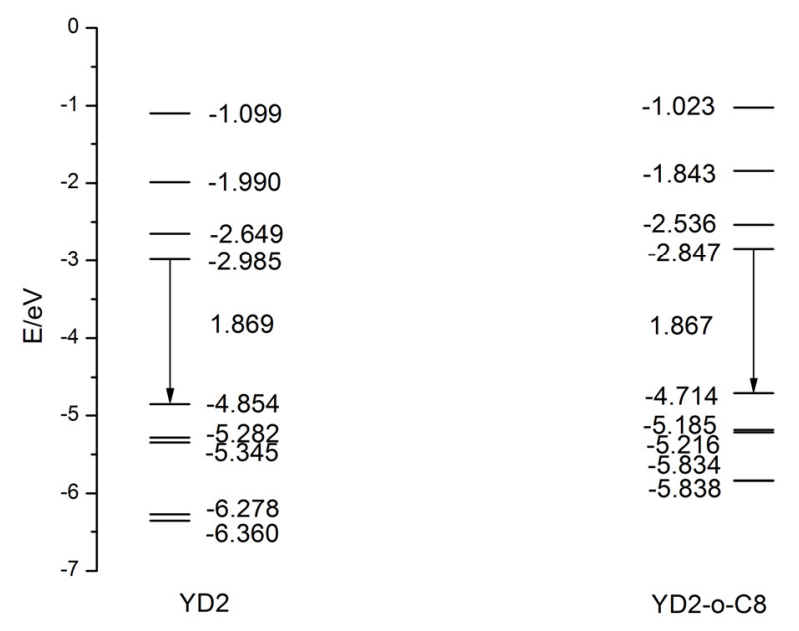

YD2 has a lower HOMO than YD2-o-C8, which results in a larger free energy change for dye regeneration $\left(\Delta G^{\text {regen }}\right)$ since the $\Delta G^{\text {regen }}$ can be determined by dye oxidation potential and redox potential 
of electrolyte [64]. Also, it should be noted that the tert-butyl groups in YD2 and the octyloxy groups in YD2o-C8 are independent of the frontier MOs. That's why the dyes have almost same HOMO-LUMO gap. The role of the tert-butyl and the octyloxy groups might be to reduce the dye aggregation and block the approach of the electrolyte to the $\mathrm{TiO}_{2}$ surface, therefore control the regeneration site of the dyes and suppress charge recombination.

Figure 4. Isodensity plots (isodensity contour $=0.02$ a.u.) of the frontier orbitals of the dye YD2 and YD2-o-C8.

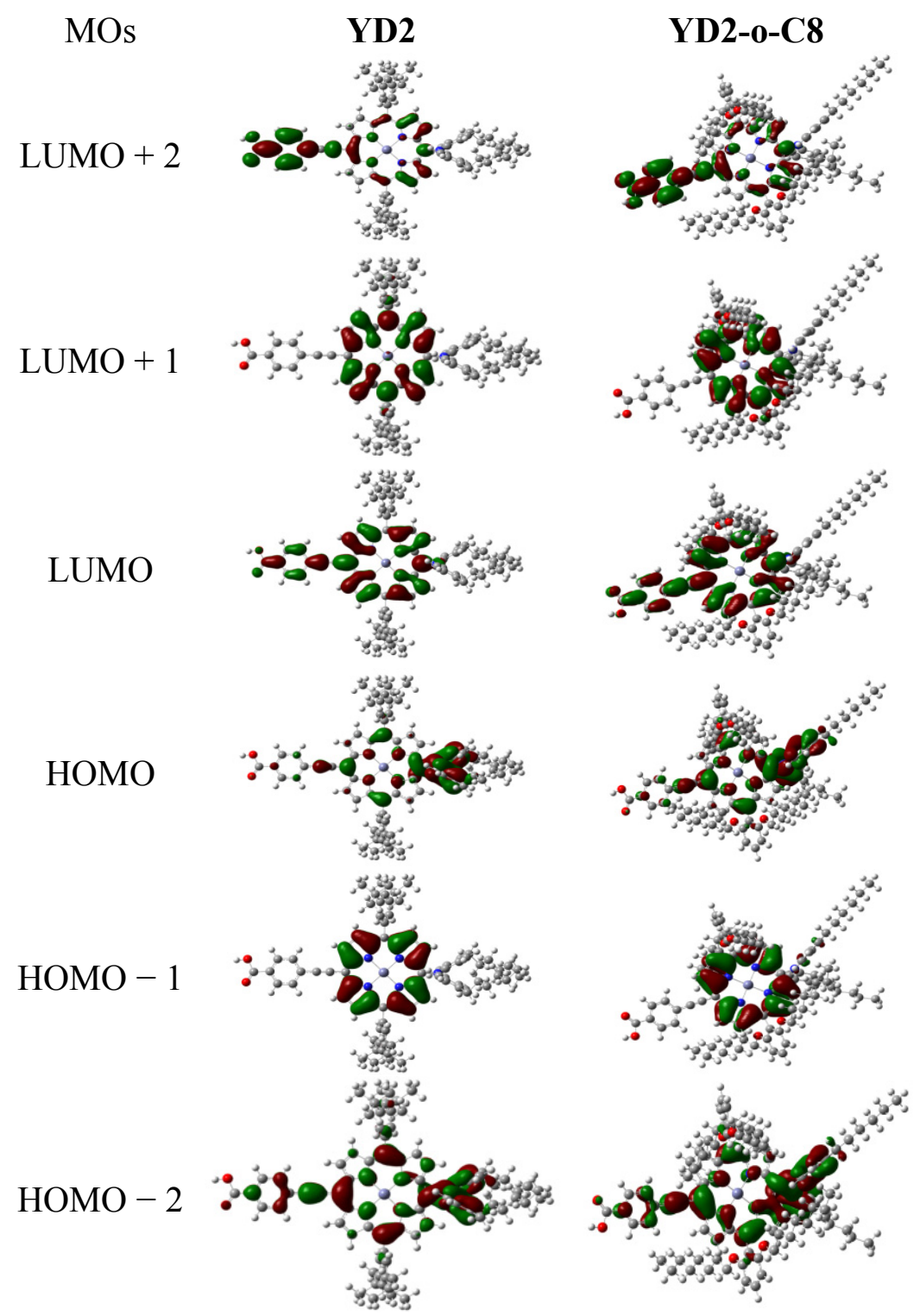

\subsection{Absorption Properties}

The absorption properties determine the capability of harvesting photons, and thus affect the performance of dye sensitizers in DSSCs. The absorption spectra of YD2 and YD2-o-C8 in UV-vis region were measured in THF solution. The experimental and the HSE06 functional calculated results are listed in Table 3, which includes the major singlet transition configurations with coefficients larger than $10 \%$ and the oscillator strength larger than 0.1 , while data calculated with other functionals are 
listed in Tables S3 and S4 in Supplementary Information. The spectral similarity of YD2 and YD2-o-C8 indicates that the substitution of tert-butyl groups in YD2 by octyloxy groups in YD2o-C8 very slightly affect the absorption properties. This can be understood from the MO analysis.

Table 3. The experimental spectra data and the HSE06 functional calculated excitation energies (eV), wavelength (nm), oscillator strengths (f) and major transition configurations with coefficients larger than 10\% in UV-vis region for YD2 and YD2-o-C8 in THF.

\begin{tabular}{|c|c|c|c|c|c|}
\hline Dyes & States & Major transition configurations & $\mathrm{E}(\mathrm{nm} / \mathrm{eV})$ & $f$ & Experimental $\lambda_{\max } / \mathrm{nm}\left(\varepsilon / 10^{3} \mathrm{M}^{-1} \mathrm{~cm}^{-1}\right)$ \\
\hline \multirow{5}{*}{ YD2 } & $\mathrm{S}_{1}$ & $\mathrm{H} \rightarrow \mathrm{L}(94 \%)$ & $677 / 1.83$ & 0.3660 & $646(34)$ \\
\hline & $\mathrm{S}_{3}$ & $H-2 \rightarrow L(78 \%) ; H-1 \rightarrow L+1(21 \%)$ & $537 / 2.31$ & 0.1294 & $586(11)$ \\
\hline & $\mathrm{S}_{5}$ & $\mathrm{H} \rightarrow \mathrm{L}+2(73 \%) ; \mathrm{H}-1 \rightarrow \mathrm{L}+1(18 \%)$ & $443 / 2.80$ & 0.7025 & \\
\hline & $\mathrm{S}_{6}$ & $\begin{array}{c}H-2 \rightarrow L+1(49 \%) ; H-1 \rightarrow L(25 \%) \\
H-1 \rightarrow L+2(10 \%)\end{array}$ & $423 / 2.93$ & 0.8193 & \\
\hline & $\mathrm{S}_{7}$ & $\begin{array}{c}\mathrm{H}-1 \rightarrow \mathrm{L}+1(39 \%) ; \mathrm{H} \rightarrow \mathrm{L}+2(21 \%) \\
\mathrm{H}-2 \rightarrow \mathrm{L}(11 \%)\end{array}$ & $423 / 2.93$ & 1.1253 & 443 (227) \\
\hline \multirow{6}{*}{ YD2-o-C8 } & $\mathrm{S}_{1}$ & $\mathrm{H} \rightarrow \mathrm{L}(93 \%)$ & $671 / 1.85$ & 0.4237 & $645(31)$ \\
\hline & $\mathrm{S}_{3}$ & $\mathrm{H}-2 \rightarrow \mathrm{L}(78 \%) ; \mathrm{H}-1 \rightarrow \mathrm{L}+1(17 \%)$ & $535 / 2.32$ & 0.1058 & $581(12)$ \\
\hline & $\mathrm{S}_{5}$ & $\mathrm{H} \rightarrow \mathrm{L}+2(70 \%) ; \mathrm{H}-1 \rightarrow \mathrm{L}+1(21 \%)$ & $442 / 2.80$ & 0.7339 & \\
\hline & $\mathrm{S}_{6}$ & $\begin{array}{c}H-2 \rightarrow L+1(38 \%) ; H-1 \rightarrow L(24 \%) ; \\
H-4 \rightarrow L(14 \%)\end{array}$ & $426 / 2.91$ & 0.5621 & \\
\hline & $\mathrm{S}_{8}$ & $\mathrm{H}-4 \rightarrow \mathrm{L}(76 \%)$ & $421 / 2.94$ & 0.1303 & \\
\hline & $\mathrm{S}_{9}$ & $\mathrm{H}-1 \rightarrow \mathrm{L}+1(42 \%) ; \mathrm{H} \rightarrow \mathrm{L}+2(25 \%)$ & $420 / 2.95$ & 1.0332 & $448(212)$ \\
\hline
\end{tabular}

The transition configurations in Table 3 and MOs in Figure 4 indicate that the overlaps between initial states to final states are highly coupled to the porphyrin ring. This again emphasizes the role of $\pi$-conjugated linker. The larger overlap based porphyrin generates larger oscillator strength and stronger absorption bands than that of D- $\pi-\mathrm{A}$ organics dyes containing other conjugated linkers, such as thiophene. To investigate the excited states properties, it is necessary to distinguish between local excitation (LE), effective charge transfer excitation (ECTE) i.e., CT excitation and extending electron distribution to anchor group of dye, ineffective CT excitation (ICTE) i.e., a CT excitation where the electron distribution does not extend to the anchor group of the dye. The transitions of the dyes that involve HOMO $-1 \rightarrow$ LUMO +1 are typical LE since the related MOs are localized in porphyrin. The relocations of the HOMOs and LUMOs in transition configurations support that the excitations have ECTE character, for instance, the transitions involving $\mathrm{HOMO} \rightarrow \mathrm{LUMO}, \mathrm{HOMO} \rightarrow \mathrm{LUMO}+2$, etc. However, the final states in transitions involving LUMO and LUMO +2 for the dyes are ECTE, while the final states in transitions involve LUMO +1 are ICTE. Apparently, the transitions that related to HOMO $-2 \rightarrow$ LUMO +1 are ICTE. The further transition configuration and MO analysis indicates that the diarylamino groups are major chromophores for ECTE, and actas electron donor in photon-induced electron injection in DSSCs. It should be noticed that the S8 state of YD2-o-C8 involving HOMO $-4 \rightarrow$ LUMO is ECTE because HOMO -4 mainly contributed by meso-phenyls in the ortho-positions and $\mathrm{O}$ in alkoxyl chains. Therefore, the meso-phenyls in the ortho-positions and $\mathrm{O}$ in alkoxyl chains in YD2-o-C8 also participate in donating electrons.

Based upon the above analysis, the number of excited states with ECTE character of YD2-o-C8 is larger than that of YD2. More ECTE is favorable for more charges of CT in DSSCs. Under the same 
experimental condition, the open-circuit voltage $\left(\mathrm{V}_{\mathrm{oc}}\right)$ and short-circuit current density $\left(\mathrm{J}_{\mathrm{sc}}\right)$ of $\mathrm{YD} 2-\mathrm{o}-\mathrm{C} 8$ is larger than that of YD2 [46].

The photo-induced electron injection in DSSCs can be viewed as a CT process. In terms of Marcus theory for electron transfer [69], the CT rate constants can be influenced by the free energy change. The free energy change for electron injection $\left(\Delta G^{\text {inject }}\right)$ affects the electron injection rate and therefore the $\mathrm{J}_{\mathrm{sc}}$ and $\mathrm{V}_{\mathrm{oc}}$ in DSSCs. Therefore, $\Delta G^{\text {inject }}$ can be viewed as the electron injection driving force [55]. The computational methods for $\Delta G^{\text {inject }}$ and the oxidation potential of excited state with ECTE character $\left(E_{O X}^{d y^{*}}\right)$ are adopted using Preat's method [53]. For the case of electron injection, which occurs from the unrelaxed excited states of dye, the $\Delta G^{\text {inject }}$ can be calculated as $\Delta G^{\text {inject }}=E_{O X}^{\text {dye* }}-E_{C B}^{S C}$. The $E_{O X}^{d y e^{*}}$ is the oxidation potential of the dye in excited states and $E_{C B}^{S C}$ is the conduction band of the semiconductor in electrode. The reported conduction band edge for $\mathrm{TiO}_{2}$ is $4.0 \mathrm{eV}$ [70]. The $E_{O X}^{d y e^{*}}$ can be calculated as $E_{O X}^{d y *^{*}}=E_{O X}^{d y e}-\lambda_{\max }$, where $E_{O X}^{d y e}$ is the oxidation potential of the ground state and $\lambda_{\max }$ is the absorption maximum with ECTE character. Due to the molecular sizes of dye sensitizers in this work, the $E_{O X}^{d y}$ is approximated by applying the Koopmann's theorem where it uses the absolute value of HOMO energy [63]. Usually, there are three absorption bands for metalloporphyrins in UV/Vis region. The prominent band to the red edge of $\mathrm{B}$ band was assigned as the $\mathrm{T}$ band [71], and the absorbance of $\mathrm{T}$ band is quite weaker than that of $\mathrm{Q}$ and $\mathrm{B}$ bands. The calculated $E_{O X}^{\text {dye* }}$ and $\Delta G^{\text {inject }}$ of Q, $\mathrm{T}$, and $\mathrm{B}$ bands for all the dyes are listed in Table 4.

Table 4. The calculated excited states oxidized potential $\left(E_{O X}^{d y y^{*}}\right.$, in $\left.\mathrm{eV}\right)$ and free energy change for electron injection $\left(\Delta G^{\text {inject }}\right.$, in $\left.\mathrm{eV}\right)$ of $\mathrm{Q}, \mathrm{T}$, and $\mathrm{B}$ absorption bands for YD2 and YD2-o-C8 dyes.

\begin{tabular}{ccccccccc}
\hline \multirow{2}{*}{ Dyes } & \multicolumn{3}{c}{$\boldsymbol{E}_{\boldsymbol{O}}^{\text {dye }}$} & & \multicolumn{4}{c}{$\boldsymbol{\Delta G}^{\text {inject }}$} \\
\cline { 2 - 4 } \cline { 7 - 8 } & $\mathbf{Q}$ & $\mathbf{T}$ & $\mathbf{B}$ & & $\mathbf{Q}$ & $\mathbf{T}$ & $\mathbf{B}$ \\
\hline YD2 & 3.02 & 2.54 & 1.92 & & -0.98 & -1.46 & -2.08 \\
YD2-0-C8 & 2.86 & 2.39 & 1.76 & & -1.14 & -1.61 & -2.24 \\
\hline
\end{tabular}

The calculated $E_{O X}^{d e^{*}}$ of $\mathrm{Q}, \mathrm{T}$, and B bands for YD2-o-C8 are smaller than that of YD2 due to its smaller ground state oxidized potential. The results in Table 4 also indicate that the $\Delta G^{\text {inject }}$ of the dyes are negative, which means that the dye excited state with ECTE character lies above the $\mathrm{TiO}_{2}$ conduction band edge. The data also suggest that the substitution of tert-butyl groups in YD2 by octyloxy groups in YD2o-C8 increase the absolute value of $\Delta G^{\text {inject }}$. The larger absolute value of $\Delta G^{\text {inject }}$ is favorable for fast electron injection, and thus for improving $\mathrm{J}_{\mathrm{sc}}$ and $\mathrm{V}_{\mathrm{oc}}$.

\section{Computational Methods}

The computations of the geometries and electronic structures for dye sensitizers were performed without any symmetry constraints using DFT in the Gaussian09 package [72]. The polarized split-valence 6-31G(d,p) basis sets are sufficient for calculating the excitation of organic dyes [73], and introducing additional diffuse functions in basis sets generate negligible effects on the electron density and hence on the accuracy of DFT and TDDFT results [57]. Therefore, the 6-31G(d,p) basis sets were adopted in the present work. The commonly referred B3LYP functional, which combines of Becke's 3-parameter 
exchange functional [74] and the correlation functional from Lee, Yang, and Parr [75], was adopted during the geometry optimization in the phase of gas and solvent because B3LYP is known to provide molecular geometries in good comparison to experiment [76]. The solvent effects were considered using a non-equilibrium version of the polarizable continuum model (PCM) [77] method. The electronic excitations were investigated using TDDFT method. Generally, for the dye sensitizers with good performance in DSSC, the electronic excitations are CT processes. However, the TDDFT calculations with conventional functionals, such as B3LYP, poorly reproduce CT excitations energies. In order to select suitable functional for the reliable description of excited properties of dye sensitizers, TDDFT were performed using different functionals, including the hybrid functionals PBE0 (25\% of Hartree-Fock exchange) [78-80], MPW1K (42\% of Hartree-Fock exchange) [81], BMK (inclusion of the kinetic energy density together with a large value of the exact exchange mixing coefficient) [82], M062X (a high nonlocality functional with double the amount of nonlocal exchange) [83], HSE06 (introducing an efficient screening technique to take advantage of the fast spatial decay of the short range Hartree-Fock exchange used in the Heyd-Scuseria-Ernzerhof screened Coulomb hybrid density functional) [84-88], and the long range corrected hybrid functional (the exchange term in the Kohn-Sham energy functional split into long-range and short-range terms) CAM-B3LYP [89], LC- $\omega$ PBE [90-93], $\omega$ B97X-D [94] with default range separation parameter, as well as LC- $\omega$ PBE with optimized range-separation parameter (denoted as OPT-LC- $\omega$ PBE). The system-dependent optimal range-separation parameter is determined by "IP tuning" procedure $[65,95,96]$, minimizing the difference between the highest occupied orbital eigenvalue $\varepsilon_{\text {НОмо }}$ and the computed ionization potential (IP) for $\omega$,

$$
\delta_{I P}(\omega)=\left|\varepsilon_{\text {HOMO }}^{\omega}-\left(E_{n}(\omega)-E_{c}(\omega)\right)\right|
$$

Here, $E_{n}$ and $E_{c}$ are total energies of neutral and cation states, respectively. The results are shown in Figure S1 in Supplementary Information (SI). Apparently, the optimized $\omega$ for YD2 and YD2-o-C8 dyes are about $0.03 \mathrm{Bohr}^{-1}$. By comparing the calculated results with experimental absorption data, the suitable functional was selected. The electronic structures and photophysical properties of YD2 and YD2-o-C8 were analyzed based upon the calculated results with the selected functional. Simulation of absorption spectra was performed using Gaussian peaks with full width at half maximum of $0.15 \mathrm{eV}$.

\section{Conclusions}

In this work, the geometries, electronic structures, and excited states properties of porphyrin dye sensitizers YD2 and YD2-o-C8 have been studied using DFT and TDDFT calculations. The calculated geometrical parameters indicate that YD2 and YD2-o-C8 have similar conjugate lengths and CT distance. According to the experimental spectra, the HSE06 functional in TDDFT is the most suitable functional for describing $\mathrm{Q}$ and $\mathrm{B}$ bands of phorphyrins. The data of electronic structures suggest that the substitution of tert-butyl groups in YD2 by octyloxy groups in YD2-o-C8 slightly affects HOMO-LUMO gap. In addition, the slightly lower HOMO of YD2, comparing that of YD2-o-C8, results in a large free energy change for dye regeneration, which is favorable for fast dye regeneration. Furthermore, the independence of the tert-butyl groups in YD2 and the octyloxy groups in YD2o-C8 on the frontier MOs suggest that the role of the tert-butyl and the octyloxy groups might be to reduce the dye aggregation and block the approach of the electrolyte to the $\mathrm{TiO}_{2}$ surface. The transition configuration and $\mathrm{MO}$ analysis supports 
that the diarylamino groups are major chromophores for ECTE, and act as the electron donor in photon-induced electron injection in DSSCs. Compared with the performance of YD2, the better performance of YD2-o-C8 results from the more excited states with ECTE character and the larger absolute value of $\Delta G^{\text {inject }}$.

\section{Acknowledgments}

This work was supported by the Basic Scientific Research Foundation for Gansu Universities of China (Grant No. 1210ZTC055), National Natural Science Foundation of China (Grant Nos. 11164016, 11164015), and scientific developmental foundation of Lanzhou University of Technology.

\section{Conflicts of Interest}

The authors declare no conflict of interest.

\section{References}

1. Gratzel, M. Photoelectrochemical cells. Nature 2001, 414, 338-344.

2. Gratzel, M. Dye-sensitized solar cells. J. Photochem. Photobiol. C 2003, 4, 145-153.

3. Li, B.; Wang, L.; Kang, B.; Wang, P.; Qiu, Y. Review of recent progress in solid-state dye-sensitized solar cells. Sol. Energy Mater. Sol. Cells 2006, 90, 549-573.

4. Nazeeruddin, M.K.; Klein, C.; Liska, P.; Gratzel, M. Synthesis of novel ruthenium sensitizers and their application in dye-sensitized solar cells. Coord. Chem. Rev. 2005, 249, 1460-1467.

5. O'Regan, B.; Gratzel, M. A low-cost, high-efficiency solar cell based on dye-sensitized colloidal $\mathrm{TiO}_{2}$ films. Nature 1991, 353, 737-740.

6. Gratzel, M. Recent advances in sensitized mesoscopic solar cells. Acc. Chem. Res. 2009, 42, 1788-1798.

7. Mishra, A.; Fischer, M.K.R.; Bauerle, P. Metal-free organic dyes for dye-sensitized solar cells: From structure: Property relationships to design rules. Angew. Chem. Int. Ed. 2009, 48, 2474-2499.

8. Ning, Z.J.; Tian, H. Triarylamine: A promising core unit for efficient photovoltaic materials. Chem. Commun. 2009, 5483-5495.

9. Robertson, N. Optimizing dyes for dye-sensitized solar cells. Angew. Chem. Int. Ed. 2006, 45, 2338-2345.

10. Zakeeruddin, S.M.; Gratzel, M. Solvent-free ionic liquid electrolytes for mesoscopic dye-sensitized solar cells. Adv. Funct. Mater. 2009, 19, 2187-2202.

11. Clifford, J.N.; Martinez-Ferrero, E.; Viterisi, A.; Palomares, E. Sensitizer molecular structure-device efficiency relationship in dye sensitized solar cells. Chem. Soc. Rev. 2011, 40, 1635-1646.

12. Chen, C.-Y.; Pootrakulchote, N.; Chen, M.-Y.; Moehl, T.; Tsai, H.-H.; Zakeeruddin, S.M.; Wu, C.-G.; Gratzel, M. A new heteroleptic ruthenium sensitizer for transparent dye-sensitized solar cells. Adv. Energy Mater. 2012, 2, 1503-1509.

13. Chen, C.-Y.; Wang, M.; Li, J.-Y.; Pootrakulchote, N.; Alibabaei, L.; Ngoc-le, C.-H.; Decoppet, J.-D.; Tsai, J.-H.; Gratzel, C.; Wu, C.-G.; et al. Highly efficient light-harvesting ruthenium sensitizer for thin-film dye-sensitized solar cells. ACS Nano 2009, 3, 3103-3109. 
14. Chen, X.Y.; Guo, J.H.; Peng, X.J.; Guo, M.; Xu, Y.Q.; Shi, L.; Liang, C.L.; Wang, L.; Gao, Y.L.; Sun, S.G.; et al. Novel cyanine dyes with different methine chains as sensitizers for nanocrystalline solar cell. J. Photochem. Photobiol. A 2005, 171, 231-236.

15. Sayama, K.; Tsukagoshi, S.; Mori, T.; Hara, K.; Ohga, Y.; Shinpou, A.; Abe, Y.; Suga, S.; Arakawa, H. Efficient sensitization of nanocrystalline $\mathrm{TiO}_{2}$ films with cyanine and merocyanine organic dyes. Sol. Energy Mater. Sol. Cells 2003, 80, 47-71.

16. Wu, W.J.; Hua, J.L.; Jin, Y.H.; Zhan, W.H.; Tian, H. Photovoltaic properties of three new cyanine dyes for dye-sensitized solar cells. Photochem. Photobiol. Sci. 2008, 7, 63-68.

17. Chen, Y.S.; Li, C.; Zeng, Z.H.; Wang, W.B.; Wang, X.S.; Zhang, B.W. Efficient electron injection due to a special adsorbing group's combination of carboxyl and hydroxyl: Dye-sensitized solar cells based on new hemicyanine dyes. J. Mater. Chem. 2005, 15, 1654-1661.

18. Wang, Z.S.; Li, F.Y.; Huang, C.H. Photocurrent enhancement of hemicyanine dyes containing $\mathrm{RSO}^{3-}$ group through treating $\mathrm{TiO}_{2}$ films with hydrochloric acid. J. Phys. Chem. B 2001, 105, 9210-9217.

19. Liang, M.; Xu, W.; Cai, F.S.; Chen, P.Q.; Peng, B.; Chen, J.; Li, Z.M. New triphenylamine-based organic dyes for efficient dye-sensitized solar cells. J. Phys. Chem. C 2007, 111, 4465-4472.

20. Shen, P.; Tang, Y.H.; Jiang, S.H.; Chen, H.J.; Zheng, X.Y.; Wang, X.Y.; Zhao, B.; Tan, S.T. Efficient triphenylamine-based dyes featuring dual-role carbazole, fluorene and spirobifluorene moieties. Org. Electron. 2011, 12, 125-135.

21. Cappel, U.B.; Karlsson, M.H.; Pschirer, N.G.; Eickemeyer, F.; Schoneboom, J.; Erk, P.; Boschloo, G.; Hagfeldt, A. A broadly absorbing perylene dye for solid-state dye-sensitized solar cells. J. Phys. Chem. C 2009, 113, 14595-14597.

22. Jiao, C.J.; Zu, N.N.; Huang, K.W.; Wang, P.; Wu, J.S. Perylene anhydride fused porphyrins as near-infrared sensitizers for dye-sensitized solar cells. Org. Lett. 2011, 13, 3652-3655.

23. Li, C.; Schoneboom, J.; Liu, Z.H.; Pschirer, N.G.; Erk, P.; Herrmann, A.; Mullen, K. Rainbow perylene monoimides: Easy control of optical properties. Chem. Eur. J. 2009, 15, 878-884.

24. Li, C.; Yum, J.H.; Moon, S.J.; Herrmann, A.; Eickemeyer, F.; Pschirer, N.G.; Erk, P.; Schoeboom, J.; Mullen, K.; Gratzel, M.; et al. An improved perylene sensitizer for solar cell applications. ChemSuschem 2008, 1, 615-618.

25. Tian, H.; Liu, P.H.; Zhu, W.H.; Gao, E.Q.; Da-Jun, W.A.; Cai, S.M. Synthesis of novel multi-chromophoric soluble perylene derivatives and their photosensitizing properties with wide spectral response for $\mathrm{SnO}_{2}$ nanoporous electrode. J. Mater. Chem. 2000, 10, 2708-2715.

26. Hara, K.; Sato, T.; Katoh, R.; Furube, A.; Ohga, Y.; Shinpo, A.; Suga, S.; Sayama, K.; Sugihara, H.; Arakawa, H. Molecular design of coumarin dyes for efficient dye-sensitized solar cells. J. Phys. Chem. B 2003, 107, 597-606.

27. Koops, S.E.; Barnes, P.R.F.; O'Regan, B.C.; Durrant, J.R. Kinetic competition in a coumarin dye-sensitized solar cell: Injection and recombination limitations upon device performance. J. Phys. Chem. C 2010, 114, 8054-8061.

28. Li, X.G.; Lu, H.J.; Wang, S.R.; Guo, J.J.; Li, J. Sensitizers of dye-sensitized solar cells. Progr. Chem. 2011, 23, 569-588. 
29. Campbell, W.M.; Burrell, A.K.; Officer, D.L.; Jolley, K.W. Porphyrins as light harvesters in the dye-sensitised $\mathrm{TiO}_{2}$ solar cell. Coord. Chem. Rev. 2004, 248, 1363-1379.

30. Hsieh, C.P.; Lu, H.P.; Chiu, C.L.; Lee, C.W.; Chuang, S.H.; Mai, C.L.; Yen, W.N.; Hsu, S.J.; Diau, E.W.G.; Yeh, C.Y. Synthesis and characterization of porphyrin sensitizers with various electron-donating substituents for highly efficient dye-sensitized solar cells. J. Mater. Chem. 2010, 20, 1127-1134.

31. Imahori, H.; Umeyama, T.; Ito, S. Large pi-aromatic molecules as potential sensitizers for highly efficient dye-sensitized solar cells. Acc. Chem. Res. 2009, 42, 1809-1818.

32. Lee, C.W.; Lu, H.P.; Lan, C.M.; Huang, Y.L.; Liang, Y.R.; Yen, W.N.; Liu, Y.C.; Lin, Y.S.; Diau, E.W.G.; Yeh, C.Y. Novel zinc porphyrin sensitizers for dye-sensitized solar cells: Synthesis and spectral, electrochemical, and photovoltaic properties. Chem. Eur. J. 2009, 15, 1403-1412.

33. Pasunooti, K.K.; Song, J.L.; Chai, H.; Amaladass, P.; Deng, W.Q.; Liu, X.W. Synthesis, characterization and application of trans-D-B-A-porphyrin based dyes in dye-sensitized solar cells. J. Photochem. Photobiol. A 2011, 218, 219-225.

34. Wu, S.L.; Lu, H.P.; Yu, H.T.; Chuang, S.H.; Chiu, C.L.; Lee, C.W.; Diau, E.W.G.; Yeh, C.Y. Design and characterization of porphyrin sensitizers with a push-pull framework for highly efficient dye-sensitized solar cells. Energy Environ. Sci. 2010, 3, 949-955.

35. Geiger, T.; Kuster, S.; Yum, J.H.; Moon, S.J.; Nazeeruddin, M.K.; Gratzel, M.; Nuesch, F. Molecular design of unsymmetrical squaraine dyes for high efficiency conversion of low energy photons into electrons using $\mathrm{TiO}_{2}$ nanocrystalline films. Adv. Funct. Mater. 2009, 19, 2720-2727.

36. Paek, S.; Choi, H.; Kim, C.; Cho, N.; So, S.; Song, K.; Nazeeruddin, M.K.; Ko, J. Efficient and stable panchromatic squaraine dyes for dye-sensitized solar cells. Chem. Commun. 2011, 47, 2874-2876.

37. Silvestri, F.; Lopez-Duarte, I.; Seitz, W.; Beverina, L.; Martinez-Diaz, M.V.; Marks, T.J.; Guldi, D.M.; Pagani, G.A.; Torres, T. A squaraine-phthalocyanine ensemble: Towards molecular panchromatic sensitizers in solar cells. Chem. Commun. 2009, 4500-4502.

38. Cheng, H.M.; Hsieh, W.F. Electron transfer properties of organic dye-sensitized solar cells based on indoline sensitizers with $\mathrm{ZnO}$ nanoparticles. Nanotechnology 2010, 21, 485202.

39. Kuang, D.; Uchida, S.; Humphry-Baker, R.; Zakeeruddin, S.M.; Gratzel, M. Organic dye-sensitized ionic liquid based solar cells: Remarkable enhancement in performance through molecular design of indoline sensitizers. Angew. Chem. Int. Ed. 2008, 47, 1923-1927.

40. Zhang, X.H.; Li, C.; Wang, W.B.; Cheng, X.X.; Wang, X.S.; Zhang, B.W. Photophysical, electrochemical, and photoelectrochemical properties of new azulene-based dye molecules. J. Mater. Chem. 2007, 17, 642-649.

41. Wu, C.-H.; Pan, T.-Y.; Hong, S.-H.; Wang, C.-L.; Kuo, H.-H.; Chu, Y.-Y.; Diau, E.W.-G.; Lin, C.-Y. A fluorene-modified porphyrin for efficient dye-sensitized solar cells. Chem. Commun. 2012, 48, 4329-4331.

42. Parussulo, A.L.A.; Iglesias, B.A.; Toma, H.E.; Araki, K. Sevenfold enhancement on porphyrin dye efficiency by coordination of ruthenium polypyridine complexes. Chem. Commun. 2012, 48, 6939-6941.

43. Campbell, W.M.; Jolley, K.W.; Wagner, P.; Wagner, K.; Walsh, P.J.; Gordon, K.C.; Schmidt-Mende, L.; Nazeeruddin, M.K.; Wang, Q.; Gratzel, M.; et al. Highly efficient porphyrin sensitizers for dye-sensitized solar cells. J. Phys. Chem. C 2007, 111, 11760-11762. 
44. Ishida, M.; Park, S.W.; Hwang, D.; Koo, Y.B.; Sessler, J.L.; Kim, D.Y.; Kim, D. Donor-substituted $\beta$-functionalized porphyrin dyes on hierarchically structured mesoporous $\mathrm{TiO}_{2}$ spheres. Highly efficient dye-sensitized solar cells. J. Phys. Chem. C 2011, 115, 19343-19354.

45. Kay, A.; Graetzel, M. Artificial photosynthesis. 1. Photosensitization of titania solar cells with chlorophyll derivatives and related natural porphyrins. J. Phys. Chem. 1993, 97, 6272-6277.

46. Yella, A.; Lee, H.W.; Tsao, H.N.; Yi, C.Y.; Chandiran, A.K.; Nazeeruddin, M.K.; Diau, E.W.G.; Yeh, C.Y.; Zakeeruddin, S.M.; Gratzel, M. Porphyrin-sensitized solar cells with cobalt (II/III)-based redox electrolyte exceed 12 percent efficiency. Science 2011, 334, 629-634.

47. Warnan, J.; Favereau L.; Meslin, F.; Severac, M.; Blart, E.; Pellegrin Y.; Jacquemin, D.; Odobel, F. Diketopyrrolopryyole-porphyrin conjugates as broadly absorbing sensitizers for dye-sensitized solar cells. ChemSusChem 2012, 5, 1568-1577.

48. Favereau, L.; Warnan, J.; Anne, F.B.; Pellegrin, Y.; Blart, E.; Jacquemin, D.; Odobel, F. Diketopyrrolopyrrole-zinc porphyrin, a tuned panchromatic association for dye-sensitized solar cells. J. Mater. Cem. A 2013, 1, 7572-7575.

49. Li, L.-L.; Diau, E.W.-G. Porphyrin-sensitized solar cells. Chem. Soc. Rev. 2013, 42, 291-304.

50. Tai, C.-K.; Chen, Y.-J.; Chang, H.-W.; Yeh, P.-L.; Wang, B.-C. DFT and TD-DFT investigations of metal-free dye sensitizers for solar cells: Effects of electron donors and $\pi$-conjugated linker. Comput. Theor. Chem. 2011, 971, 42-50.

51. Kim, B.-G.; Zhen, C.-G.; Jeong, E.J.; Kieffer, J.; Kim, J. Organic dye design tools for efficient photocurrent generation in dye-sensitized solar cells: Exciton binding energy and electron acceptors. Adv. Funct. Mater. 2012, 22, 1606-1612.

52. Zhang, C.-R.; Liu, L.; Liu, Z.-J.; Shen, Y.-L.; Sun, Y.-T.; Wu, Y.-Z.; Chen, Y.-H.; Yuan, L.-H.; Wang, W.; Chen, H.-S. Electronic structures and optical properties of organic dye sensitizer NKX derivatives for solar cells: A theoretical approach. J. Mol. Graphics Modell. 2012, 38, 419-429.

53. Preat, J.; Michaux, C.; Jacquemin, D.; Perpète, E.A. Enhanced efficiency of organic dye-sensitized solar cells: Triphenylamine derivatives. J. Phys. Chem. C 2009, 113, 16821-16833.

54. Fan, W.; Tan, D.; Deng, W. Theoretical investigation of triphenylamine dye/titanium dioxide interface for dye-sensitized solar cells. Phys. Chem. Chem. Phys. 2011, 13, 16159-16167.

55. Fan, W.; Tan, D.; Deng, W.-Q. Acene-modified triphenylamine dyes for dye-sensitized solar cells: A computational study. ChemPhysChem 2012, 13, 2051-2060.

56. Zhang, C.-R.; Liu, L.; Zhe, J.-W.; Jin, N.-Z.; Ma, Y.; Yuan, L.-H.; Zhang, M.-L.; Wu, Y.-Z.; Liu, Z.-J.; Chen, H.-S. The role of the conjugate bridge in electronic structures and related properties of tetrahydroquinoline for dye sensitized solar cells. Int. J. Mol. Sci. 2013, 14, 5461-5481.

57. Pastore, M.; Mosconi, E.; de Angelis, F.; Gratzel, M. A Computational investigation of organic dyes for dye-sensitized solar cells: Benchmark, strategies, and open issues. J. Phys. Chem. C 2010, 114, 7205-7212.

58. Lu, H.-P.; Tsai, C.-Y.; Yen, W.-N.; Hsieh, C.-P.; Lee, C.-W.; Yeh, C.-Y.; Diau, E.W.-G. Control of dye aggregation and electron injection for highly efficient porphyrin sensitizers adsorbed on semiconductor films with varying ratios of coadsorbate. J. Phys. Chem. C 2009, 113, 20990-20997. 
59. Barea, E.M.; Gonzalez-Pedro, V.; Ripolles-Sanchis, T.; Wu, H.P.; Li, L.L.; Yeh, C.Y.; Diau, E.W.G.; Bisquert, J. Porphyrin dyes with high injection and low recombination for highly efficient mesoscopic dye-sensitized solar cells. J. Phys. Chem. C 2011, 115, 10898-10902.

60. Wang, C.-L.; Lan, C.-M.; Hong, S.-H.; Wang, Y.-F.; Pan, T.-Y.; Chang, C.-W.; Kuo, H.-H.; Kuo, M.-Y.; Diau, E.W.-G.; Lin, C.-Y. Enveloping porphyrins for efficient dye-sensitized solar cells. Energy Envir. Sci. 2012, 5, 6933-6940.

61. Chang, Y.-C.; Wang, C.-L.; Pan, T.-Y.; Hong, S.-H.; Lan, C.-M.; Kuo, H.-H.; Lo, C.-F.; Hsu, H.-Y.; Lin, C.-Y.; Diau, E.W.-G. A strategy to design highly efficient porphyrin sensitizers for dye-sensitized solar cells. Chem. Commun. 2011, 47, 8910-8912.

62. Ripolles-Sanchis, T.; Guo, B.-C.; Wu, H.-P.; Pan, T.-Y.; Lee, H.-W.; Raga, S.R.; Fabregat-Santiago, F.; Bisquert, J.; Yeh, C.-Y.; Diau, E.W.-G. Design and characterization of alkoxy-wrapped push-pull porphyrins for dye-sensitized solar cells. Chem. Commun. 2012, 48, 4368-4370.

63. Lee, M.-J.; Balanay, M.; Kim, D. Molecular design of distorted push-pull porphyrins for dye-sensitized solar cells. Theor. Chem. Acc. 2012, 131, 1269.

64. Zhang, C.-R.; Liu, L.; Zhe, J.-W.; Jin, N.-Z.; Yuan, L.-H.; Chen, Y.-H.; Wei, Z.-Q.; Wu, Y.-Z.; Liu, Z.-J.; Chen, H.-S. Comparative study on electronic structures and optical properties of indoline and triphenylamine dye sensitizers for solar cells. J. Mol. Model. 2013, 19, 1553-1563.

65. Körzdörfer, T.; Sears, J.S.; Sutton, C.; Brédas, J.-L. Long-range corrected hybrid functionals for $\pi$-conjugated systems: Dependence of the range-separation parameter on conjugation length. J. Chem. Phys. 2011, 135, 204107.

66. Nazeeruddin, M.K.; Kay, A.; Rodicio, I.; Humphrybaker, R.; Muller, E.; Liska, P.; Vlachopoulos, N.; Gratzel, M. Conversion of light to electricity by cis-X ${ }_{2}$ bis(2,2'-bipyridyl-4,4'dicarboxylate)Ruthenium(II) charge-transfer sensitizers $\left(X=\mathrm{Cl}^{-}, \mathrm{BR}^{-}, \mathrm{I}^{-}, \mathrm{CN}^{-}\right.$, and $\left.\mathrm{SCN}^{-}\right)$on nanocrystalline $\mathrm{TiO}_{2}$ electrodes. J. Am. Chem. Soc. 1993, 115, 6382-6390.

67. Kurashige, Y.; Nakajima, T.; Kurashige, S.; Hirao, K.; Nishikitani, Y. Theoretical investigation of the excited states of coumarin dyes for dye-sensitized solar cells. J. Phys. Chem. A 2007, 111, 5544-5548.

68. Zhou, W.P.; Cao, Z.C.; Jiang, S.H.; Huang, H.Y.; Deng, L.J.; Liu, Y.J.; Shen, P.; Zhao, B.; Tan, S.T.; Zhang, X.X. Porphyrins modified with a low-band-gap chromophore for dye-sensitized solar cells. Org. Electron. 2012, 13, 560-569.

69. Marcus, R.A. Electron transfer reactions in chemistry. Theory and experiment. Rev. Mod. Phys. 1993, 65, 599-610.

70. Asbury, J.B.; Wang, Y.-Q.; Hao, E.; Ghosh, H.N.; Lian, T. Evidences of hot excited state electron injection from sensitizer molecules to $\mathrm{TiO}_{2}$ nanocrystalline thin films. Res. Chem. Intermed. 2001, 27, 393-406.

71. Lind, S.J.; Gordon, K.C.; Gambhir, S.; Officer, D.L. A spectroscopic and DFT study of thiophene-substituted metalloporphyrins as dye-sensitized solar cell dyes. Phys. Chem. Chem. Phys. 2009, 11, 5598-5607.

72. Gaussian09 package, Revision C.01; Gaussian, Inc.: Wallingford, CT, USA, 2010.

73. Jacquemin, D.; Perpète, E.A.; Ciofini, I.; Adamo, C. Accurate simulation of optical properties in dyes. Acc. Chem. Res. 2008, 42, 326-334. 
74. Becke, A.D. Density-functional thermochemistry. III. The role of exact exchange. J. Chem. Phys. 1993, 98, 5648-5652.

75. Lee, C.T.; Yang, W.T.; Parr, R.G. Development of the colle-salvetti correlation-energy formula into a functional of the electron-density. Phys. Rev. B 1988, 37, 785-789.

76. Sousa, S.F.; Fernandes, P.A.; Ramos, M.J. General performance of density functionals. J. Phys. Chem. A 2007, 111, 10439-10452.

77. Cossi, M.; Barone, V. Separation between fast and slow polarizations in continuum solvation models. J. Phys. Chem. A 2000, 104, 10614-10622.

78. Perdew, J.P.; Burke, K.; Ernzerhof, M. Generalized gradient approximation made simple. Phys. Rev. Lett. 1996, 77, 3865-3868.

79. Perdew, J.P.; Burke, K.; Ernzerhof, M. Generalized gradient approximation made simple [Phys. Rev. Lett. 77, 3865 (1996)]. Phys. Rev. Lett. 1997, 78, 1396.

80. Adamo, C.; Barone, V. Toward reliable density functional methods without adjustable parameters: The PBE0 model. J. Chem. Phys. 1999, 110, 6158-6170.

81. Lynch, B.J.; Fast, P.L.; Harris, M.; Truhlar, D.G. Adiabatic connection for kinetics. J. Phys. Chem. A 2000, 104, 4811-4815.

82. Boese, A.D.; Martin, J.M.L. Development of density functionals for thermochemical kinetics. J. Chem. Phys. 2004, 121, 3405-3416.

83. Zhao, Y.; Truhlar, D.G. Comparative DFT study of van der waals complexes: Rare-gas dimers, alkaline-earth dimers, zinc dimer, and zinc-rare-gas dimers. J. Phys. Chem. A 2006, 110, 5121-5129.

84. Henderson, T.M.; Izmaylov, A.F.; Scalmani, G.; Scuseria, G.E. Can short-range hybrids describe long-range-dependent properties? J. Chem. Phys. 2009, 131, 044108-044109.

85. Heyd, J.; Scuseria, G.E. Assessment and validation of a screened Coulomb hybrid density functional. J. Chem. Phys. 2004, 120, 7274-7280.

86. Heyd, J.; Scuseria, G.E.; Ernzerhof, M. Hybrid functionals based on a screened Coulomb potential. J. Chem. Phys. 2003, 118, 8207-8215.

87. Izmaylov, A.F.; Scuseria, G.E.; Frisch, M.J. Efficient evaluation of short-range Hartree-Fock exchange in large molecules and periodic systems. J. Chem. Phys. 2006, 125, 104103-104108.

88. Krukau, A.V.; Vydrov, O.A.; Izmaylov, A.F.; Scuseria, G.E. Influence of the exchange screening parameter on the performance of screened hybrid functionals. J. Chem. Phys. 2006, $125,224105-224106$.

89. Yanai, T.; Tew, D.P.; Handy, N.C. A new hybrid exchange-Correlation functional using the Coulomb-attenuating method (CAM-B3LYP). Chem. Phys. Lett. 2004, 393, 51-57.

90. Vydrov, O.A.; Scuseria, G.E.; Perdew, J.P. Tests of functionals for systems with fractional electron number. J. Chem. Phys. 2007, 126, 154109.

91. Vydrov, O.A.; Scuseria, G.E. Assessment of a long-range corrected hybrid functional. J. Chem. Phys. 2006, 125, 234109.

92. Vydrov, O.A.; Heyd, J.; Krukau, A.V.; Scuseria, G.E. Importance of short-range versus long-range Hartree-Fock exchange for the performance of hybrid density functionals. J. Chem. Phys. 2006, 125, 074106.

93. Tawada, Y.; Tsuneda, T.; Yanagisawa, S.; Yanai, T.; Hirao, K. A long-range-corrected time-dependent density functional theory. J. Chem. Phys. 2004, 120, 8425-8433. 
94. Chai, J.D.; Head-Gordon, M. Long-range corrected hybrid density functionals with damped atom-atom dispersion corrections. Phys. Chem. Chem. Phys. 2008, 10, 6615-6620.

95. Refaely-Abramson, S.; Baer, R.; Kronik, L. Fundamental and excitation gaps in molecules of relevance for organic photovoltaics from an optimally tuned range-separated hybrid functional. Phys. Rev. B 2011, 84, 075144.

96. Sears, J.S.; Koerzdoerfer, T.; Zhang, C.-R.; Bredas, J.-L. Orbital instabilities and triplet states from time-dependent density functional theory and long-range corrected functionals. J. Chem. Phys. 2011, 135, 151103.

(C) 2013 by the authors; licensee MDPI, Basel, Switzerland. This article is an open access article distributed under the terms and conditions of the Creative Commons Attribution license (http://creativecommons.org/licenses/by/3.0/). 